(c) The Author(s) 2016. This is an Open Access article, distributed under the terms of the Creative Commons Attribution licence (http://creativecommons. org/licenses/by/4.0/), which permits unrestricted re-use, distribution, and reproduction in any medium, provided the original work is properly cited.

\title{
A satellite-derived glacier inventory for North Asia
}

\author{
Lucas EARL, ${ }^{1}$ Alex GARDNER ${ }^{2}$ \\ ${ }^{1}$ Graduate School of Geography, Clark University, Worcester, MA, USA \\ ${ }^{2}$ Jet Propulsion Laboratory, California Institute of Technology, Pasadena, CA, USA \\ Correspondence: Alex Gardner <alex.s.gardner@jpl.nasa.gov>
}

\begin{abstract}
This study outlines a consistent methodology for identifying glacier surfaces from Landsat 5, 7 and 8 imagery that is applied to map all mainland North Asian glaciers, providing the first methodologically consistent and complete glacier inventory for the region $\sim 2010$. We identify 5065 glaciers covering a planimetric area of $2326 \pm 186 \mathrm{~km}^{2}$, most of which is located in the Altai mountain subregion. The total glacier count is $15 \%$ higher, but the total glacier area is $32 \pm 11.6 \%$ lower, than the estimated glacier coverage provided in version 4.0 of the Randolph Glacier Inventory. We investigate the distribution of glacier size within North Asia and find that the majority of glaciers $(82 \%)$ are smaller than $0.5 \mathrm{~km}^{2}$ but only account for a third of the total glacier area, with the largest $1 \%(60$ glaciers $\geq 5 \mathbf{k m}^{2}$ ) accounting for $28 \%$ of the total area. We present hypsometric characterizations of North Asian glaciers, largely substantiating existing findings that glaciers in this region are dominated by cold, relatively dry conditions. We provide a detailed assessment of errors and determine the uncertainty in our area estimate to be $\pm \mathbf{8 . 0} \%$, with snow-cover uncertainty the largest contributing factor. Based on this assessment, the new glacier inventory presented here is more complete and of higher quality than other currently available data sources.
\end{abstract}

KEYWORDS: climate change, glacier delineation, glacier mapping, mountain glaciers, remote sensing

\section{INTRODUCTION}

Alpine glaciers are an important component of the global hydrologic cycle. Glaciers can help to regulate streamflows in regions where water is stored during cold wet times of the year and later released as meltwater runoff during warm dry conditions (Beniston, 2003). Alpine glaciers also provide proxy information on regional and global climate where other long-term records may not exist, as changes in glacier mass and/or extent can reflect changes in temperature and/ or precipitation (e.g. Oerlemans and Fortuin, 1992; Meier and others, 2007; Leclercq and others, 2011).

Despite the interest in glacier change and subsequent research, inventories of alpine glaciers often focus on a limited region because of data, time or other resource constraints (e.g. Sidjak and Wheate, 1999; Paul and others, 2002; Narama and others, 2009; Konya and others, 2014). Where study regions have overlapped, differences in methodologies have resulted in discrepancies in glacier outlines (Paul, 2000; Paul and others, 2013). To support more comprehensive alpine glacier research, complete and methodologically consistent inventories of glacier locations and outlines are needed on larger scales.

The Randolph Glacier Inventory (RGl) attempts to solve many of these problems by providing a near globally complete baseline dataset of glacier outlines. It overcomes the slow assembly of the Global Land Ice Measurements from Space (GLIMS) database by prioritizing complete coverage at the cost of reduced attribute information (Pfeffer and others, 2014). While the RGI provides data for most glacial regions of the world, its quality is variable. One of the poorest-quality regions is North Asia, where explicit glacier outlines are missing in many areas. For this reason RGI version 4.0 (www.glims.org/RGI/) uses 'nominal glaciers' for which only records of a point location and total glacier area exist. These glaciers are represented as circles, where the centre is a pair of coordinates representing the glacier location and the radius of the circle is chosen to give an area that matches the glacier record. Though nominal glaciers are useful for tabulating regional totals for a global context, they provide little value at the regional level as they lack meaningful geographical reference (Pfeffer and others, 2014). In total, RGI 4.0 contains $2940\left(1879 \mathrm{~km}^{2}\right)$ nominal glaciers, of which $2832\left(1868 \mathrm{~km}^{2}\right)$ are located in North Asia, comprising $54 \%$ of the total glacier area for this region (Pfeffer and others, 2014). The other global database, GLIMS, contains an incomplete dataset for North Asia. A portion of the Cherskiy ranges (Fig. 1) has been included, as has much of the Altai mountains. However, based on visual comparison to L1T Landsat 5, 7 and 8 imagery, many of the outlines in the Russian and Chinese Altai are poorly georeferenced, and those in Mongolia date from 1989 (GLIMS and NSIDC, 2005).

Motivated by the variable quality and dates of data in existing global inventories for North Asian glaciers, this study sets out to map all glaciers in the North Asia region from moderate resolution $(30 \mathrm{~m})$ satellite imagery for the $\sim 2010$ epoch using a well-tested and consistent methodology. While we provide a complete glacier inventory of North Asian glaciers from imagery acquired between 1999 and 2013, we make no investigation of glacial change.

\section{BACKGROUND}

\section{Study area}

The North Asia study region (RGI region 10; Fig. 1) covers mainland north and northeast Asia. The region is bounded by the Altai mountains in the south, the Ural Mountains in the west, the Arctic Ocean in the north, and the Bering Sea and Pacific Ocean in the east. Most of the study area falls within Russia, but parts of China, Kazakhstan and Mongolia are also included. Only a few mountain ranges are high enough to support glaciers; winter temperatures and thus 


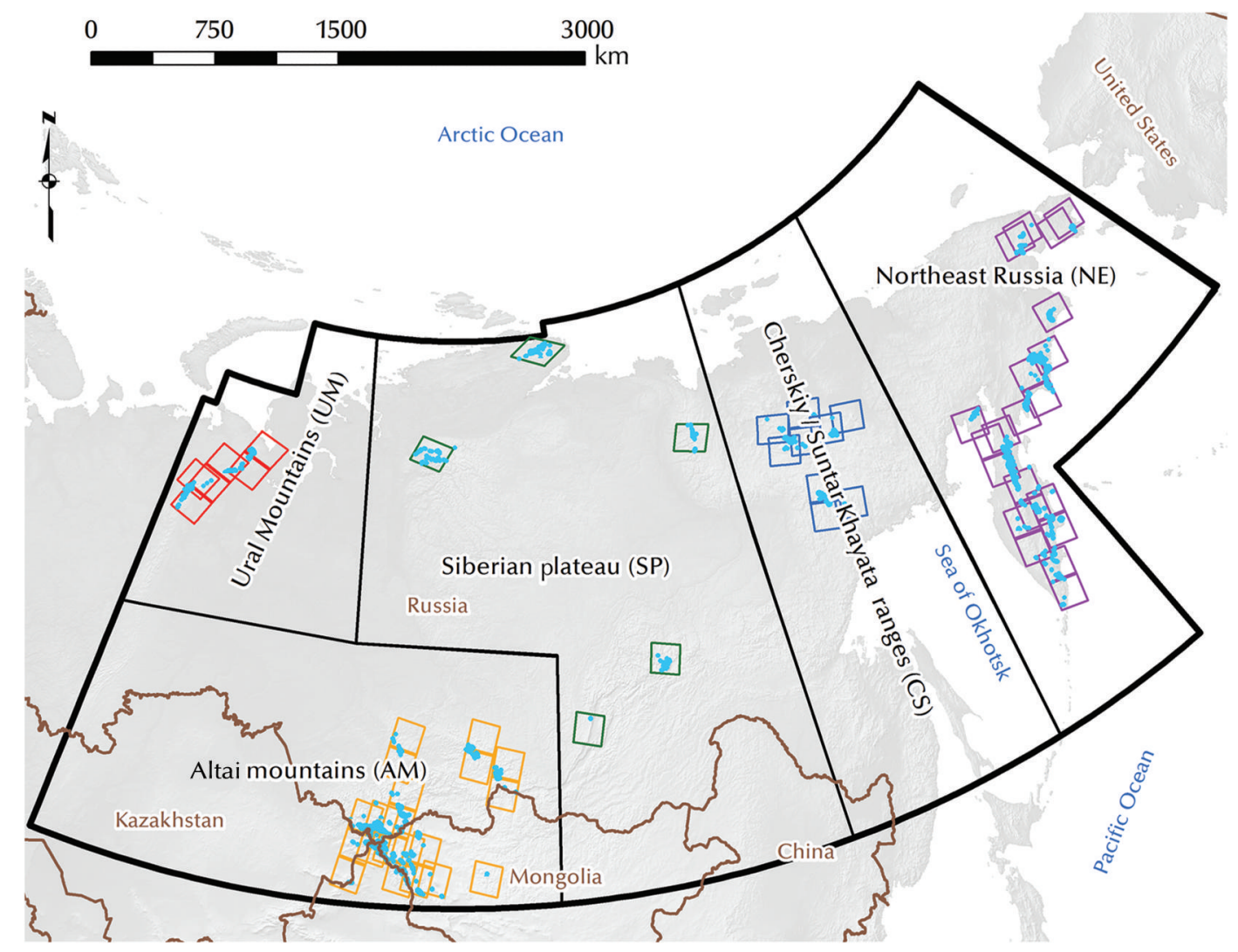

Fig. 1. North Asia study region divided into five subregions: Altai mountains (AM); Cherskiy/Suntar Khayata ranges (CS); northeast Russia (NE); Siberian plateau (SP); and Ural Mountains (UM). Final C4 glacier outlines have been superimposed in light blue; Landsat scene footprints are shown as rectangles coloured by subregion.

winter precipitation totals across much of the region are very low (Shahgedanova, 2002). Islands in the Russian Arctic are excluded, as they are located within a separate RGI region (region 9).

The North Asia region is extensive and experiences a varied climatology. To better classify regional geography we further divided the region into five subregions (Fig. 1): the Ural mountains (UM) in the west; the Altai mountains (AM) in the south; the Cherskiy and Suntar Khayata ranges (CS) in the northeast; and northeast Russia (NE) in the far east. A fifth 'catch-all' subregion, the Siberian plateau (SP), includes a few glaciers isolated from the rest (Fig. 1).

A comprehensive campaign to inventory the glaciers of the USSR, primarily from air photographs, began in 1962 and was mostly complete by the 1980s (Kotlyakov, 1980; Kotlyakov and others, 2005; Khromova and others, 2014). While glacier outlines were not published, detailed information on glacier area, aspect, elevation, type and location was published by the USSR (now Russian) Academy of Sciences (Kotlyakov, 1980), with data relevant to North Asia contained in volumes 15-20 (WGMS, 1989). Most of these data are summarized in the Former Soviet Union section in the Satellite image atlas of gaciers of the world (Kotlyakov and others, 2005). Table 1 provides total glacier area measurements by subregion from this and other sources. While region-wide studies of glacial change have been limited, those that do exist indicate that glacier retreat has occurred in most areas throughout the 20th century, primarily in response to increases in summer air temperature (Khromova and others, 2014). A summary of glacier changes by subregion is also provided in Table 1 .
While subregional inventories and change analyses are well represented in North Asia through the 20th century, a comprehensive modern inventory for the entire area is lacking. The most recent release of the RGI (4.0) measures the glaciated area in all of North Asia at $3435 \pm 354 \mathrm{~km}^{2}$ and the glacier count at 4403 .

\section{Previous research}

The AM subregion contains the most southerly glaciers in North Asia and reaches across four countries (China, Mongolia, Kazakhstan and Russia; Fig. 1). RGI 4.0 contains 2207 glaciers in this subregion, with a total area of $1803 \mathrm{~km}^{2}$ (Pfeffer and others, 2014; Table 2). Most studies have found that glaciers retreated during the 20th century in response to higher summer temperatures, with an acceleration of loss in the past three decades (Kadota and Gombo, 2007; Surazakov and others, 2007; Shahgedanova and others, 2010; Zhang and others, 2012; Kamp and others, 2013; Osipov and Osipova, 2014; Table 1). Taken together, these studies have provided a complete glacier inventory for the AM subregion. The satellite image atlas of glaciers of the world in its Chinese subsection includes a brief discussion of part of the Altai mountains, as well as a longer summary in the Russian subsection, both providing a glacier count and area (Kotlyakov and others, 2005; Shi and others, 2005; Table 1). Nuimura and others (2014) provide a complete glacier inventory (including glacier outlines) of High Mountain Asia, in which the AM subregion is included.

The CS subregion is located in northeastern Siberia, to the northwest of the Sea of Okhotsk (Fig. 1). RGI 4.0 contains 425 glaciers in this subregion, with a total area of $371 \mathrm{~km}^{2}$ 
Table 1. Existing glacier area and area change measurements for North Asia. Khromova and others (2014) rely mostly on the Glacier Inventory of the USSR

\begin{tabular}{|c|c|c|c|c|c|c|}
\hline & \multirow[t]{2}{*}{ Source (period) } & \multicolumn{5}{|c|}{ Subregion } \\
\hline & & AM & CS & NE & SP & UM \\
\hline Glacier area $\left(\mathrm{km}^{2}\right)$ & $\begin{array}{l}\text { Khromova and others, } 2014(1940-70) \\
\text { Kadota and Gombo, } 2007(1970-71)^{1} ; \\
\text { Shi and others, } 2005(1982)^{1}\end{array}$ & $\begin{array}{l}960 \text { (Russia); } \\
287 \text { (Mongolia); } \\
297 \text { (China) }\end{array}$ & 357 & $1195^{2}$ & 70 & 29 \\
\hline \multirow[t]{3}{*}{ Area loss rate $\left(\%\right.$ change $\left.\mathrm{a}^{-1}\right)$} & $\begin{array}{l}\text { Gurney and others, } 2008 \text { (1850-2001) } \\
\text { Kadota and Gombo, } 2007 \text { (1970-2000) } \\
\text { Khromova and others, } 2014 \text { (1952-2004; } \\
\text { 1950-2002; 1953-2000) }\end{array}$ & $\begin{array}{c}- \\
0.70^{4} \\
0.38^{5}\end{array}$ & $\begin{array}{c}0.11^{3} \\
- \\
-\end{array}$ & $\begin{array}{c}- \\
- \\
0.32\end{array}$ & $\begin{array}{l}- \\
- \\
-\end{array}$ & $\begin{array}{c}- \\
- \\
0.47\end{array}$ \\
\hline & $\begin{array}{l}\text { Osipov and Osipova, } 2014(1850-2011) \\
\text { Shahoedanova }\end{array}$ & - & - & - & $0.27^{6}$ & $\begin{array}{c}- \\
0.47 \pm 0.08^{7}\end{array}$ \\
\hline & $\begin{array}{l}\text { Shahgedanova and others, } 2012(1953-2000) \\
\text { Stokes and others, } 2013(1963-2010)\end{array}$ & $\begin{array}{l}- \\
-\end{array}$ & $\begin{array}{l}- \\
-\end{array}$ & $\begin{array}{l}- \\
-\end{array}$ & $0.94 \pm 0.09^{8}$ & $\begin{array}{l}0.4 / \pm 0.08 \\
-\end{array}$ \\
\hline
\end{tabular}

Estimates for: ${ }^{1} \mathrm{AM}$ subregion only; ${ }^{2}$ some area calculation $1980-90 ;{ }^{3}$ Buordakh massif and Cherskiy ranges only; ${ }^{4}$ Mongolian Altai only; ${ }^{5}$ Russian Altai only; ${ }^{6}$ Kodar, Eastern Sayan and Baikalskiy ranges only; ${ }^{7}$ northern Urals only; ${ }^{8}$ Kodar range only.

(Pfeffer and others, 2014; Table 2). Glaciers have been in a state of retreat since the end of the Little Ice Age (mid1800s), and research suggests that glaciers in the southeast will experience greater rates of retreat through the end of the 21 st century relative to the subregion's glaciers as a whole (Ananicheva and others, 2005, 2008). Portions of this subregion are among the few parts of North Asia that are currently represented in GLIMS, and a relatively recent ( 2000) partial inventory ( $35 \%$ of total coverage) for glaciers in this subregion has been completed (Gurney and others, 2008).

The NE subregion encompasses the Kamchatka peninsula and the Koryak mountains, as well as some smaller glaciers to the northeast in extreme eastern Siberia (Fig. 1). RGI 4.0 has 1462 glaciers in this subregion, with a total area of $1177 \mathrm{~km}^{2}$ (Pfeffer and others, 2014; Table 2). Despite the extent of glaciation in this part of North Asia, research has been mostly limited to the Kamchatka peninsula, with initial subregion-wide glacier identification not completed until 1990 (Kotlyakov and others, 2005, 2011). Ananicheva and others (2008) documented recent glacial advance, while others have observed various rates of retreat (Table 1 ) that are attributed to increases in summer temperature and decreases in snowfall (Muraviev and Nosenko, 2013; Khromova and others, 2014).

The SP subregion consists of four distinct, if small, glaciated mountain ranges (the Byrranga mountains, Kodar range, Orulgan range and Putorana plateau) in central Siberia (Fig. 1). RGI 4.0 contains 228 glaciers in this subregion, with a total area of $67 \mathrm{~km}^{2}$ (Pfeffer and others,
2014; Table 2). Recent research in the southeastern portion of the SP subregion has concluded that glacier area shrank at an average rate of $0.37 \% \mathrm{a}^{-1}$ over the 20th century, with an acceleration to $3.39 \% \mathrm{a}^{-1}$ in the past decade and an expectation that retreat will continue through the near future (Shahgedanova and others, 2011; Stokes and others, 2013; Osipov and Osipova, 2014). Complete disappearance or evolution into rock glaciers of some glaciers in this subregion by mid- to late century is also expected (Ananicheva and others, 2008; Stokes and others, 2013). Glaciers in the Byrranga mountains were discovered in 1949 and included in the first Russian Glacier Inventory (Kotlyakov and others, 2005). Glaciers on the Putorana plateau remain largely unstudied, though investigation of WorldView imagery available in Google Earth revealed a few small glaciers at the present time that have not been included in previous inventories.

The UM subregion is located in the far western portion of the North Asia study area, along the traditional border with Europe (Fig. 1). RGI 4.0 contains 85 glaciers in this subregion, with a total area of $18 \mathrm{~km}^{2}$. Unlike some other subregions, glacier presence in the Urals depends almost entirely on blowing-snow accumulation on leeward slopes, rather than direct deposition (Dolgushin, 1961). Recent studies have found glacier retreat is widespread across the subregion, with the total disappearance of some glaciers since observations began in the early 20th century (Shahgedanova and others, 2012); this follows similar trends earlier in the 20th century (Aleshkoff, 1933; Dolgushin, 1961).

Table 2. Comparison of C4 glacier counts and area (from this study) with RGI counts and area (as reported in Pfeffer and others, 2014)

\begin{tabular}{|c|c|c|c|c|c|c|}
\hline Subregion & C4 glacier count & $\begin{array}{l}\text { C4 area } \\
\mathrm{km}^{2}\end{array}$ & RGI glacier count & $\begin{array}{l}\text { RGI glacier area } \\
\mathrm{km}^{2}\end{array}$ & $\begin{array}{c}\text { RGI to C4 difference (count) } \\
\qquad \%\end{array}$ & $\begin{array}{c}\text { RGI to C4 difference (area) } \\
\qquad \%\end{array}$ \\
\hline AM & 2446 & $1163 \pm 102$ & 2207 & $1803 \pm 186$ & $+11 \%$ & $-35 \%$ \\
\hline CS & 420 & $204 \pm 20$ & 425 & $371 \pm 38$ & $-1 \%$ & $-45 \%$ \\
\hline NE & 1641 & $879 \pm 86$ & 1462 & $1177 \pm 121$ & $+12 \%$ & $-25 \%$ \\
\hline SP & 393 & $64 \pm 7$ & 228 & $67 \pm 7$ & $+72 \%$ & $-4 \%$ \\
\hline UM & 161 & $15 \pm 2$ & 85 & $18 \pm 2$ & $+89 \%$ & $-17 \%$ \\
\hline Total & 5065 & $2326 \pm 186$ & 4407 & $3436 \pm 354$ & $+15 \%$ & $-32 \%$ \\
\hline
\end{tabular}




\section{DATA}

\section{RGI 4.0 glacier outlines}

Existing RGI 4.0 outlines for the North Asia region were downloaded from the RGI website (www.glims.org/RGI/). RGI outlines were derived from GLIMS outlines that were available in 2012, as well as from the World Glacier Inventory (WGI) and WGI-extended format (WGI-XF) (WGMS, 1989; Cogley, 2009). The latter two sources provided tables of glacier locations and attributes and were used to assign nominal glacier locations and areas. The RGI outlines were used to help identify imagery footprints that likely contained glacier ice, but since most of the data were nominal, they were not used for validation of our inventory (see supplementary information, Fig. S1 (available online at http://www.igsoc.org/hyperlink/71a008_supp.pdf)).

\section{Landsat imagery}

For this study we used Landsat 5 Thematic Mapper (TM), Landsat 7 Enhanced TM Plus (ETM+) and Landsat 8 Operational Land Imager (OLI) data (30 m resolution). Pure snow and clean ice are highly reflective across the visible (VIS) spectrum. This is contrasted with strong absorption at the shortwave infrared (SWIR) wavelengths, which makes the utilization of both in concert well suited for glacier classification (e.g. Paul, 2000). The following band combinations were used: Landsat $5 / 7$ bands $3(0.63-0.69 \mu \mathrm{m})$ and $5(1.55-1.75 \mu \mathrm{m})$; and Landsat 8 bands $4(0.64-0.67 \mu \mathrm{m})$ and $6(1.57-1.65 \mu \mathrm{m})$.

Landsat data were downloaded from the United States Geological Survey (USGS) Earth Resources Observation Systems (EROS) Center (glovis.usgs.gov). A total of 87 footprints were initially identified as likely to contain glaciers by comparing footprints with RGI 4.0 glacier locations, while another 7 were identified based on the literature and visual inspection. Of the 94 footprints, 83 were found to contain contemporary $(\sim 2010)$ glaciers at a size detectable by the TM, ETM+ and OLI sensors $\left(0.01 \mathrm{~km}^{2}\right.$; Paul, 2000). For these 83 footprints, imagery was selected that best suited highquality analysis for distinguishing glacier from non-glacier surfaces, i.e. late in the ablation season, containing minimal cloud and shadowing, and as recent as possible, with a preference for Landsat $8 \mathrm{OLI}$ imagery (which has better radiometric resolution ( 12 bits as opposed to 8 bits) than the other Landsat sensors). While newer imagery was prioritized over older imagery, many footprints lacked high-quality images, and so imagery used in this study has acquisition dates between 1999 and 2013 (see Table S1 (http://www. igsoc.org/hyperlink/71a008_supp.pdf)).

In total we identified 88 images for analysis (Table S1). The difference between the number of images and the number of footprints is attributable to the fact that several footprints (path(P)142 $\operatorname{row}(\mathrm{R}) 27, \mathrm{P} 142 \mathrm{R} 025, \mathrm{P} 137 \mathrm{R} 024$, P091R013, P087R014) required multiple images for adequate coverage due to seasonal snow or partial cloud cover. Of these 88, 31 were from Landsat 8 OLI (2013), 17 from Landsat 7 ETM+ (1999-2002) and 40 from Landsat 5 TM (2002-11) sensors. Landsat 7 data after May 2003 were not used due to the failure of the scan-line corrector and resultant striping. All Landsat imagery was preprocessed by the USGS to correct for terrain distortion, at either the L1Gt (geometric and topographic correction using a digital elevation model (DEM)) or L1T (geometric and topographic correction using a DEM and ground-control points) levels
(Welch and others, 1985). All images had geolocation inaccuracies of less than the width of a single pixel $(<30 \mathrm{~m})$.

\section{METHODS}

The delineation method can be summarized as follows. Upper and lower threshold values were used to classify snow and ice surfaces from images of normalized-difference snow index (NDSI). An additional threshold using the blue band (0.43-0.45 for Landsat 8, 0.45-0.52 for Landsat 5 and 7) was used to improve the identification of rock in shadow. Following this automated process, glacier outlines were manually corrected using first a Landsat composite then the highest-resolution imagery available in Google Earth. Google Earth imagery was also used to identify debris cover on glaciers $>2.5 \mathrm{~km}^{2}$. Figure 2 shows a full schematic of the automated and manual workflow.

\section{Automated classification}

\section{Landsat image preprocessing}

All L1T and L1Gt imagery was atmospherically corrected using a dark-object subtraction method that uses measured radiance observed over dark surfaces (deep clear lakes or dark objects in shadow) to estimate scattering by the atmosphere (Chavez, 1988). Despite the high initial quality of the Landsat images, there was still image radiance variation due to residual atmospheric effects, which were removed using the dark-object subtraction method.

\section{NDSI and window selection}

Using information contained in the measured VIS and SWIR wavelengths, there are a variety of ways to discriminate glacier surfaces (see Paul (2000) and Racoviteanu and others (2008) for thorough reviews). Motivated by the size of our study area, and the interest in generating reproducible outlines, we chose to adopt a semi-automated methodology.

The most common semi-automated approach to identify glacier surfaces involves applying a threshold to the NDSI (Williams and others, 1991):

$$
\mathrm{NDSI}=\frac{(\text { red }- \text { SWIR })}{(\text { red }+ \text { SWIR })}
$$

Use of non-NDSI threshold methods has been successful (e.g. Gratton and others, 1990; Aniya and others, 1996; Sidjak and Wheate, 1999; Paul and others, 2002; Bolch and others, 2008), but in our investigation these did not significantly improve outline accuracy. A thresholding method was selected to efficiently classify glacier surfaces. While most modern versions of the NDSI use the green band instead of the red (USGS, 2013), we found little difference between results derived using red or green bands.

An NDSI window between 0.50 and 0.99 was found to exclude non-ice surfaces with low values as well as silty lakes, which tend to have NDSI values near unity and frequently are confused with snow and ice using NDSI thresholding methods (Huggel and others, 2002; Bolch and others, 2008). Upper and lower window bounds were identified through trial and error on an initial test Landsat 8 image and applied across all imagery following dark-object subtraction. 0.50 was found to be the best cut-off between darker ice surfaces and non-glacier land cover.

Lakes are typically less reflective in the red than the SWIR (resulting in NDSI values $<0$ ), but silty lakes can be much 


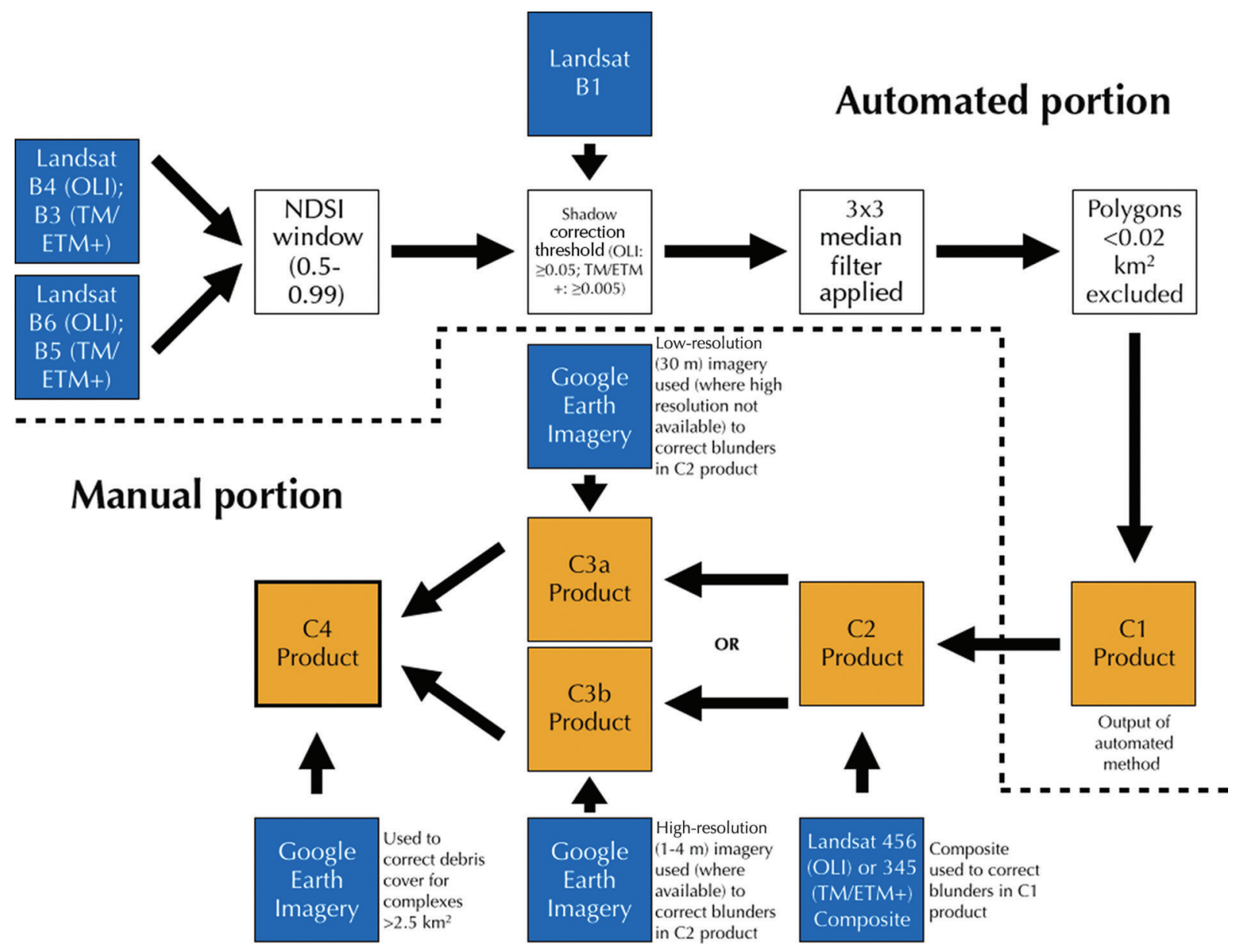

Fig. 2. Glacier classification workflow. Blue squares represent input imagery; white boxes processing steps; and orange boxes output products.

more reflective at red wavelengths due to the presence of glacial rock flour or other reflecting impurities. This results in positive NDSI values near 1 for these surfaces, as the SWIR terms are near zero. By setting an upper bound on the NDSI threshold, we avoided inaccurate classification of silty lakes as glacier ice while retaining snow and ice surfaces. A value of 0.99 was chosen based on trial and error; it represents the lowest possible value for an upper limit without excluding the brightest pure snow surfaces within the North Asia region.

To our knowledge the use of an upper NDSI threshold to improve glacier classification is novel, so we provide a detailed visualization of its impact on the classification results in Figure 3. Figure 3a compares glacierized areas in a heavily shadowed region of the AM subregion (P144R026). While areas in shadow are excluded when the upper threshold is applied, comparison with higher-resolution imagery in Google Earth indicated that most area excluded was rock in shadow, rather than glacier. Figure 3c highlights a different area of the same Landsat image where shadowing is minimal, which is better representative of the whole study region. Figure $3 \mathrm{~b}$ highlights a silty lake in the same Landsat image, where inclusion of the upper threshold removes most of the lake surface, as compared with no upper threshold.

Landsat 5 TM and Landsat 7 ETM+ sample different wavelengths and have a coarser radiometric resolution than Landsat 8 , so the following changes were made to the delineation approach for images acquired by these sensors: TM/ETM+ bands 3 and 5 were used for the NDSI (window
0.5-0.99). Landsat 5 and 7 thresholds were developed interactively with an image for the similar geographic area in the same subregion (AM, P145R025).

\section{Additional automated constraints}

We applied a number of additional constraints to the NDSI calculation to further improve the classification of glacierized surfaces. Using OLI band 1 values above 0.05 as a mask helped to eliminate rock in shadow that had been erroneously selected as snow/ice using the NDSI window, as snow and ice surfaces had slightly higher reflectances in this band, even in shadow. Landsat 5 and 7 band 1 (blue) was used in place of the coastal band 1 in Landsat 8 (blue is assigned to band 2 in Landsat 8) for shadow correction, with a threshold of $\geq 0.005$. A $3 \times 3$ median filter was applied to the classification results to remove erroneous snow and ice pixels that were identified in isolation (e.g. Svoboda and Paul, 2009). This common practice did not noticeably impact errors of omission.

\section{Conversion to polygons}

The delineation method produced a Boolean raster output of glacier-covered area, which was converted to a vector polygon layer. This layer contained polygons representing glacier complexes, defined as 'the generic term for all collections of glaciers that meet at [flow] divides' (Cogley and others, 2011). Complexes $<0.02 \mathrm{~km}^{2}$ were then excluded as with Landsat imagery it is difficult to differentiate between small glaciers and snowpatches (Svoboda and Paul, 2009). 


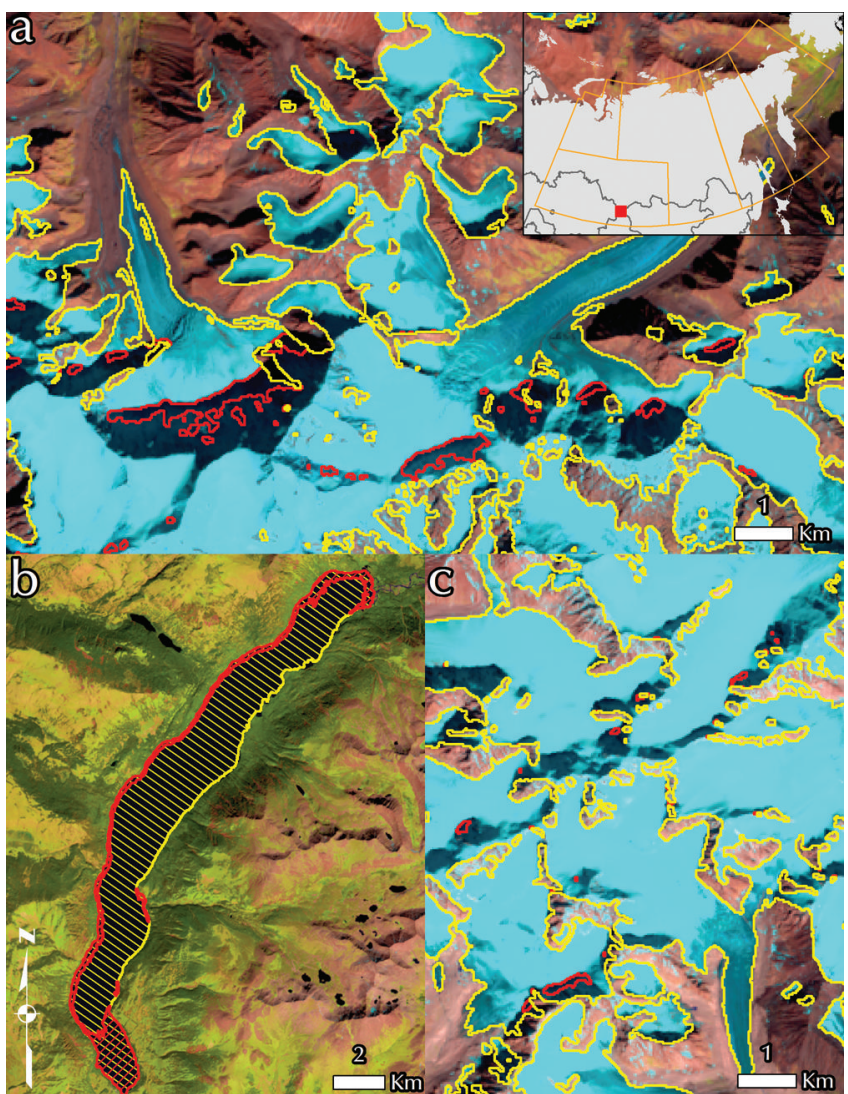

Fig. 3. Comparison of $\mathrm{C} 1$ outlines with (red) and without (yellow) upper NDSI threshold. Examples of (a) excluded rock in shadow, (b) excluded silty lake (hatching indicates area delimited) and (c) area mostly devoid of shadowing. All examples from the AM subregion (P144R026).

\section{Post-classification corrections}

Some classification errors could not be resolved without manual correction. Figure 4 shows some of the common problems that remain after applying the automated identification methodology: exclusion of debris-covered glaciers (Fig. 4a), exclusion of glaciers in extreme shadow (Fig. 4b), inclusion of seasonal snow (Fig. 4c) and inclusion of some sediment-laden lakes (Fig. 4d). The problems apparent in Figure $4 \mathrm{~b}$ and $\mathrm{d}$ remained despite efforts to correct them in the automated portion of the delineation: extreme shadows (especially in north-facing cirques) had no radiance information, meaning glaciers could not be classified, while the most turbid lakes had identical NDSI signatures to snow and ice surfaces. Problems in Figure $4 \mathrm{a}$ and $\mathrm{c}$ are well documented as barriers to glacier classification using fully automated methodologies (e.g. Racoviteanu and others, 2009). Therefore, the automatic classification results were further refined through manual inspection by the operator, using the original Landsat imagery as well as higherresolution imagery available through Google Earth.

\section{C1 and C2 outlines}

To standardize the manual correction, we separated the stages of correction into four correction levels (C1-C4) for each Landsat image. C1 was the raw output from the automated glacier identification as described above. C2 outlines were corrected based on visual interpretation of a false-colour composite of the Landsat imagery from which the original outlines were derived. During this correction,

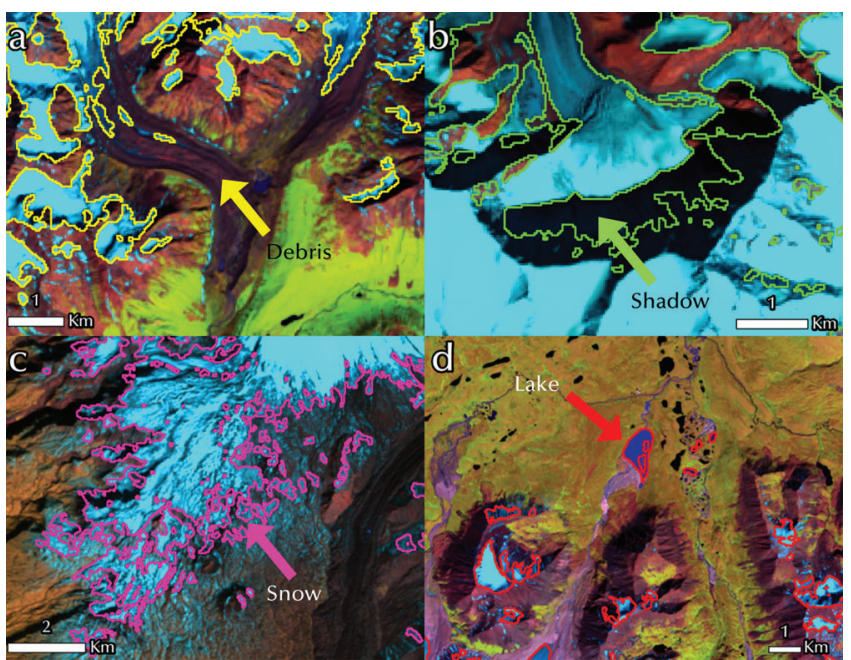

Fig. 4. Classification errors following automated delineation in part of the AM subregion: (a) incorrect exclusion of debris cover; (b) incorrect exclusion of ice in extreme shadow (beyond that corrected using the upper threshold in Fig. 2); (c) incorrect inclusion of seasonal snow; and (d) incorrect inclusion of silty lakes. Outlines are: C1, Landsat P144R026 for (a), (b) and (d) (AM subregion); Landsat P098R021 for (c) (NE subregion).

spectrally similar features that were classified as glaciers were removed, including: silty lakes (easily discriminated based on landscape location), sea ice (in the SP and UM subregions where Landsat scenes extended over the ocean), aufeis (present in the CS and NE subregions at lower elevations), and seasonal snow on non-mountainous terrain. For the most part, snow on glacier tongues was not problematic due to the use of late-season imagery, but where this did occur (e.g. due to avalanching) outlines were altered only where snow overlaid debris-covered ice, in order to accurately quantify the latter. In all cases, if it was not clear whether a feature was glacier ice, we deferred a decision to the next level of correction.

\section{C3 outlines}

C3 outlines were further corrected using available imagery in Google Earth, subdivided between C3a (Landsat imagery $(30 \mathrm{~m})$ in Google Earth) and C3b (high-resolution imagery (1-4 m) in Google Earth). C2 outlines were converted to Keyhole Markup Language (KML) format, exported to Google Earth and compared side by side (visually) with the original C2 outlines in ArcGIS. Glacier ice was added where shadow or cloud obscured glacier surfaces in the parent Landsat imagery, and removed where seasonal snow had been incorrectly delineated by the automated method. The C3 correction was used only to identify and remove errors and not for fine adjustment of glacier extents that might differ due to differences in image dates. Nearly all Google Earth imagery was acquired within 5 years of the parent Landsat imagery. No alterations were made to the C2 outlines where the available Google Earth imagery was separated in time by $>5$ years.

\section{C4 outlines (debris-cover correction)}

At the C4 level, outlines were corrected for debris cover using available Google Earth imagery, at the same spatial resolution as was available for $\mathrm{C} 3$. Identifying debris cover using remotely sensed imagery is notoriously difficult and 
Table 3. Assessment glacier inventory area uncertainty

\begin{tabular}{lcccc}
\hline $\begin{array}{l}\text { Submethod/ } \\
\text { condition }\end{array}$ & $\begin{array}{c}\text { Automated } \\
\text { method used }\end{array}$ & $\begin{array}{c}\text { Alternative } \\
\text { method }\end{array}$ & Error type & $\begin{array}{c}\text { Derived } \\
\text { uncertainty }\end{array}$ \\
$\%$
\end{tabular}

time-consuming (e.g. Bolch and others, 2008; Racoviteanu and others, 2008). Due to the difficulties in distinguishing debris cover from surrounding rock moraines for smaller complexes, and to keep the work effort manageable (e.g. Sidjak and Wheate, 1999; Paul, 2000; Paul and others, 2002; Svoboda and Paul, 2009), we limited the classification of debris cover to complexes $>2.5 \mathrm{~km}^{2}$. We found high-resolution imagery, such as that available in Google Earth, could be used to identify debris-covered glacier surfaces. Crevasses, lateral moraines and stream emergence from debris-covered tongues were all identifiable for those outlines for which high-resolution Google Earth imagery (C3b) was available. In areas without higher-resolution imagery (e.g. Landsat, C3a; Paul and others, 2004), shadowing due to a break in slope or convex tongues revealed debris-covered glaciers. We acknowledge that there are partially debris-covered glacier complexes $<2.5 \mathrm{~km}^{2}$ in North Asia, but it is only above this threshold that we can be confident in the accuracy of our C4 outlines given the imagery available.

To summarize, Google Earth imagery was used only to remove classification errors and to identify debris-covered glacier ice; C1-C4 glacier outlines are representative of the originating Landsat imagery dates in all cases where debris cover was not present. The extent of mapped debris-covered area is representative of the period 2004-13, which is the period over which all imagery used to map debris cover was acquired. While debris cover may have increased during this time period based on the observed retreat of glaciers in this area, the degree of this change is likely small. For C2C4, we follow the methodology outlined above; however, proper discrimination of glacier ice from seasonal snow was often based on operator experience, rather than a strictly defined set of rules. The same operator made all manual corrections, to ensure consistency across the entire study area (Bolch and others, 2008).

The final step in creating the inventory required merging glacier complex outlines from each individual Landsat image into subregions and then for all of North Asia; where scenes overlapped, the image with less snow cover was preferred. As differences in snow cover typically had a greater effect on the delineation of glacier outlines than real changes in glacier extent, the newer image was given priority only if the difference in imagery dates was $>5$ years.

\section{Division of glacier complexes into individual glaciers}

For this study we applied the semi-automated method developed by Kienholz and others (2013) to subdivide the glacier complexes into individual glaciers. This approach uses a modified DEM to calculate flowsheds for glacier complexes, before merging flowsheds constituting a single glacier, thus avoiding errors from the application of classic hydrological flowshed algorithms. We used the Advanced Spaceborne Thermal Emission and Reflection Radiometer (ASTER) global DEM version 2 (GDEMv2), mosaicked by subregion. GDEMv2 has a horizontal resolution of $30 \mathrm{~m}$ (projected to $\sim 27 \mathrm{~m}$ ), which is sufficient for glacier delineation (Kienholz and others, 2013).

Glacier divides were then visually inspected for errors. Kienholz and others (2013) report delineation errors between 2 and $3 \%$ of total glacierized area, and while we did not assess errors for this portion of the method, qualitative inspection revealed that complexes were subdivided along clearly defined topographic divides in most cases. We did only a small amount of manual correction, where gentle relief led the semi-automated method to identify divides incorrectly.

\section{Analysis of uncertainties}

Random or systematic uncertainties in derived outlines were assessed for several test regions (Table 3). The impact of debris-covered area cut-off was examined in three locations: two in the AM subregion (P145R027 and P144R026) and one in the CS subregion (P114R016). Inclusion of debris-covered glaciers for exposed ice complexes $<2.5 \mathrm{~km}^{2}$ increased the total glacier area in all cases by an area-weighted average of $1 \%$. This error is included as a systematic uncertainty in our area estimates. Uncertainties introduced by manual correction of the automated classification results were assessed for three sets of Landsat 8 images that overlapped in the same path (images acquired within minutes of each other) to control for image conditions (P144R026 and P144R025, P143R025 and P143R024, and P114R016 and P114R017). The first pair was for an area of more difficult correction (greater debris cover, greater shadowing), while the second and third pairs were more representative of the entire study area. Area differences varied between 3.3 and $10.9 \%$, the greatest for the third pair likely due to the small glacier area considered $\left(3.84 \mathrm{~km}^{2}\right)$, which is more influenced by small discrepancies in area. Comparison of final outlines between Landsat 7 and Landsat 8 imagery (at P144R026 and P144R025 for 4 September and 27 August 2013) revealed similar percentage area differences, indicating that sensor differences had little impact on the classification of glacier extents. The results of these five test pairs were area-averaged to give a mean uncertainty of $5.3 \%$. This uncertainty is considered to be random between image scenes. Use of the red instead of the green for the visible band in the calculation of NDSI was compared for two portions of the AM subregion (P145R027 and P144R026). Differences were minimal, with a glacier area-averaged uncertainty of $0.1 \%$. This uncertainty is considered to be random between image scenes. The applied methodology greatly reduced the effect of image condition (e.g. seasonal snow cover, illumination, atmospheric effects) through the manual selection of imagery and comparison with imagery in Google Earth. However, image condition introduces additional uncertainties that are difficult to rigorously quantify without a validation dataset. We therefore assigned an additional systematic uncertainty of $5 \%$ for image condition as we expect poor image condition to generally result in an overestimate of glacier area. 


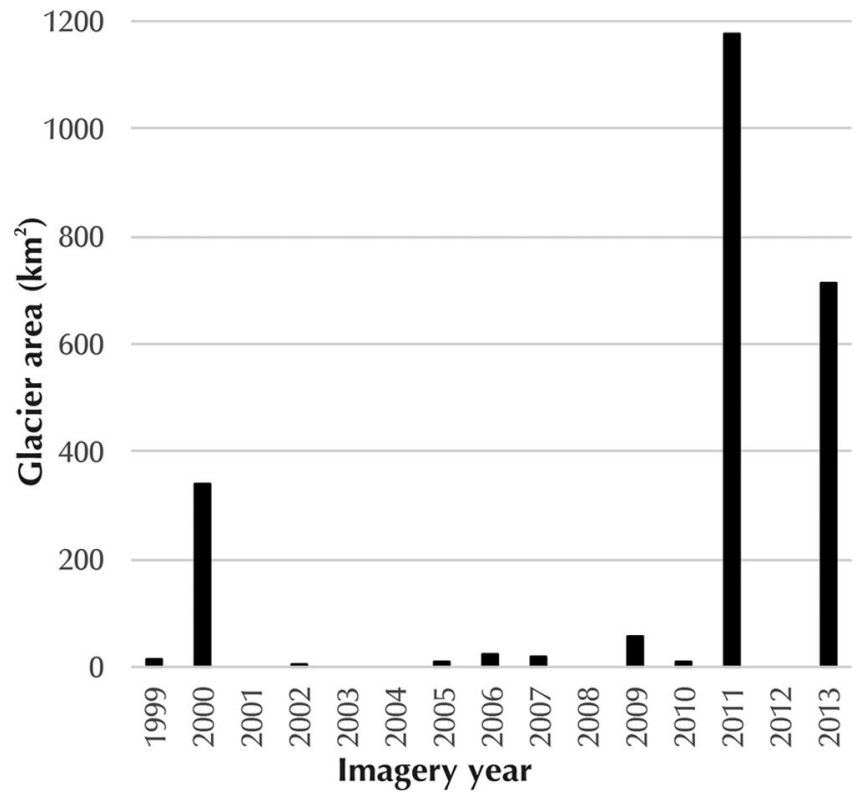

Fig. 5. Area contribution to the North Asia inventory grouped by year of image acquisition.

While the most recent imagery was prioritized in the generation of the inventory, cloud cover and/or snow cover sometimes forced the use of older imagery. Figure 5 shows the total glacier area derived from imagery acquired in any given year. $80 \%$ of the total glacier area is derived from imagery acquired within the 4 year interval 2011-14, with the remaining $20 \%$ (mostly from the NE subregion) derived from imagery acquired between 1999 and 2010. To determine the potential error associated with the range in imagery dates, the area-averaged uncertainty introduced for each image used in the inventory was estimated using

$$
\frac{\sum_{i=1}^{n}\left|a_{i} \times \mathrm{d} T_{i} \times r_{i}\right|}{\sum_{i=1}^{n} a_{i}}
$$

where $a_{i}$ is the glacier area contribution from image $i, \mathrm{~d} T_{i}$ is the difference in date from the representative date of the inventory (area-weighted average date $=2010$ ), $r_{i}$ is the measured rate of change for each subregion $\left(\% \mathrm{a}^{-1}\right)$ as determined from the literature (Table 1 ), and $n$ is the count of images used in the inventory. The absolute value of the measured area change for each image is taken as a liberal estimate of the total change since this implies that glacier shrinkage occurred prior to the representative date of the inventory and glacier expansion occurred after. The measured date-induced uncertainty was highest for the NE subregion and smallest for the AM subregion. Equation (2) represents an extreme case where glacier shrinkage occurred prior to the representative date of the inventory and glacier expansion occurred after. If we assume a constant rate of glacier shrinkage across the full range of imagery dates then there would be zero uncertainty introduced by the breadth of imagery dates since the representative date of the inventory is the area-weighted average date. We therefore scale by half the total inventory uncertainty $(1.1 \%)$ calculated using Eqn (2) to provide a more realistic estimate of the uncertainty introduced by image dates. As a result, a value of $0.6 \%$ was included as a systematic uncertainty. It should be noted that date-induced uncertainties for the entire inventory are much smaller than uncertainties introduced from image condition.
Table 4. Summary of glaciers, glacier area, average area, debris area, and debris cover percentage, arranged subregionally for the North Asia study region. See also Table 2

\begin{tabular}{lccccc}
\hline Subregion & $\begin{array}{c}\text { C4 glacier } \\
\text { count }\end{array}$ & $\begin{array}{c}\mathrm{C} 4 \text { area } \\
\mathrm{km}^{2}\end{array}$ & $\begin{array}{c}\text { Average } \\
\text { glacier area } \\
\mathrm{km}^{2}\end{array}$ & $\begin{array}{c}\text { Debris } \\
\text { area } \\
\mathrm{km}^{2}\end{array}$ & $\begin{array}{c}\text { Debris } \\
\text { cover } \\
\%\end{array}$ \\
\hline $\mathrm{AM}$ & 2446 & $1163 \pm 102$ & 0.475 & $42 \pm 4$ & 3.6 \\
$\mathrm{CS}$ & 420 & $204 \pm 20$ & 0.486 & $2.2 \pm 0.2$ & 1.1 \\
$\mathrm{NE}$ & 1641 & $879 \pm 86$ & 0.535 & $90 \pm 9$ & 10.0 \\
$\mathrm{SP}$ & 393 & $64 \pm 7$ & 0.164 & - & - \\
UM & 161 & $15 \pm 2$ & 0.092 & - & - \\
Total & 5065 & $2326 \pm 186$ & 0.459 & $134 \pm 11$ & 5.7 \\
\hline
\end{tabular}

The glacier area uncertainty for each image $\left(U_{n}\right)$ was defined as the sum of the random $\left(U r_{n}\right)$ and systematic $\left(U s_{n}\right)$ uncertainties

$$
\begin{gathered}
U_{n}=A_{n} \times \sqrt{U_{\mathrm{b}}^{2}+U_{\mathrm{m}}^{2}} \\
U \mathrm{~s}_{n}=A_{n} \times\left(U_{\mathrm{sc}}+U_{\mathrm{da}}+U_{\mathrm{db}}\right)
\end{gathered}
$$

where $A_{n}$ is the glacier area derived from image $n, U_{\mathrm{b}}$ is the uncertainty introduced from the selection of the visible band in the calculation of NDSI (red vs green, $0.1 \%$ ), $U_{m}$ is the uncertainty introduced during the manual correction of the automatically classified outlines $(5.3 \%), U_{\mathrm{sc}}$ is the uncertainty introduced by image conditions $(5 \%),, U_{\mathrm{da}}$ is the uncertainty from differences in imagery dates (differs for each region, $0.6 \%$ total inventory), and $U_{\mathrm{db}}$ is the uncertainty introduced by the exclusion of debris cover for complexes $<2.5 \mathrm{~km}^{2}(1.0 \%)$. For any set of images (or region) the uncertainty was defined as

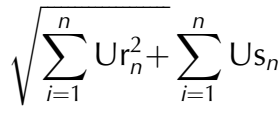

Uncertainty for each subregion individually was 8.8\% (AM), 9.7\% (CS), 9.8\% (NE), $11.3 \%(\mathrm{SP})$ and $10.4 \%(\mathrm{UM})$, and $8.0 \%$ for the entire inventory. The largest contribution to the uncertainty (5\%) comes from image condition, a conclusion that is supported by Svoboda and Paul (2009) and suggests that improvements in the North Asia inventory will come primarily through higher-quality imagery.

\section{RESULTS}

\section{Glacier area and count}

Summary statistics for the entire glacier inventory are provided in Table 4, while Figure $6 \mathrm{a}$ and b contain information regarding glacier count and area distribution by size class. North Asian glaciers cover an area of $2326 \pm 186 \mathrm{~km}^{2}$. This is $1104 \pm 400 \mathrm{~km}^{2}$ (32 $\left.\pm 11.6 \%\right)$ lower glacier coverage than for the same region in RGI 4.0, a value greater than the uncertainty stated for this region $(10.3 \%$; Pfeffer and others, 2014). The difference in dates and imperfections in the RGI inventory (misidentification and poor geolocation of nominal glaciers) are the likely causes of the difference between total North Asia glacier area measurements. Problems with accuracy of RGl 4.0 glacier outlines and the overestimation of nominal glacier areas, as evident in Figure S1 (http://www.igsoc.org/hyperlink/ 

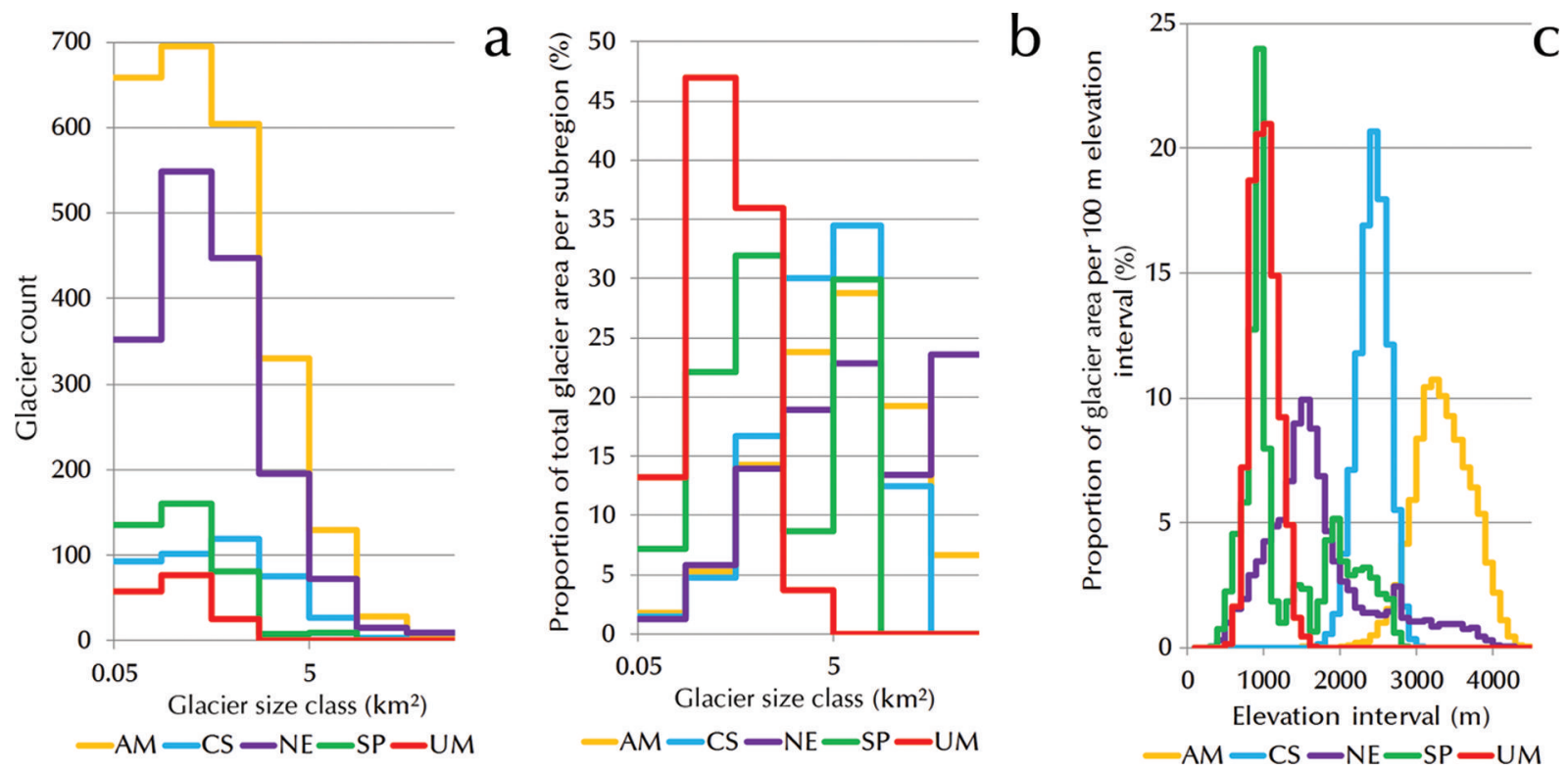

Fig. 6. Characteristics of glaciers in North Asia. (a) Comparison of glacier count distribution, grouped by size class, for each subregion; (b) comparison of glacier area distribution (as a percentage of total area per subregion), grouped by size class, for each subregion; (c) hypsometric analysis for glaciers in North Asia for each subregion.

71a008_supp.pdf), also contribute to differences between inventories. In addition, we identified 5065 glaciers, which is $662(15 \%)$ more than are identified in RGl 4.0 (Pfeffer and others, 2014).

The AM subregion contains the largest glacier area of all five subregions: $50 \%$ of the total glacierized area of North Asia. The NE subregion had the second highest coverage $(38 \%)$, with the other three subregions making up the remaining $12 \%$. Figure 7 compares debris-covered area (for glaciers $>2.5 \mathrm{~km}^{2}$ ) to total glacier area for the entire study area and by subregion. Debris cover was most extensive in the NE subregion $(10 \%)$, less so in the AM subregion $(3.6 \%)$ and minimal in the CS subregion (1.1\%). There were no glacier complexes larger than $2.5 \mathrm{~km}^{2}$ in either the SP or UM

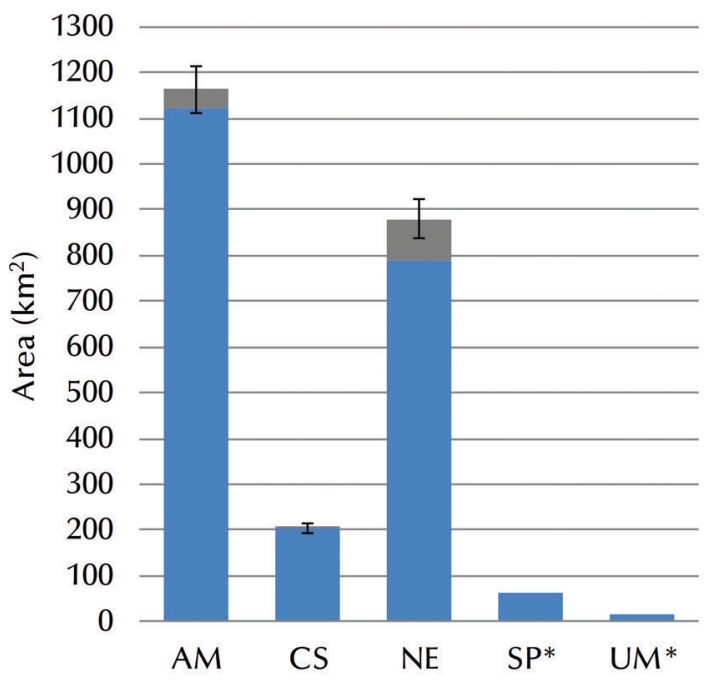

- Exposed snow and ice Debris cover**

Fig. 7. Total glaciated area for North Asia, stratified by subregion. Error bars are for the total assessed error for each subregion. *Debris cover not mapped. **Debris cover mapped only for glacier complexes $\geq 2.5 \mathrm{~km}^{2}$. subregions, so debris cover was not mapped for these glaciers. While previous studies have indicated debris cover is present in the SP subregion (e.g. Stokes and others, 2013; Osipov and Osipova, 2014) the small contribution of overall clean-ice area to the study area total $(\sim 2.8 \%)$ makes the exclusion of debris a small uncertainty.

\section{Hypsometry}

Figure 6c displays the results from our hypsometric analysis. The CS and UM subregions both had near-normal, unimodal distributions, with peaks in glacier area at 2400$2500 \mathrm{~m}$ and $1000-1100 \mathrm{~m}$, respectively. The AM subregion distribution was also unimodal, though its peak is skewed towards higher elevations, reflecting the presence of a number of high-elevation massifs. The NE and SP subregions have distinct peaks, but with secondary peaks as well. In the NE subregion, glacier area peaks at the 1400-1700 m range, but with a secondary peak at 2700-2800 m reflective of the few large glaciated volcanic cones. As the SP subregion contains mountain ranges in relatively disparate locations, the peak at $900-1000 \mathrm{~m}$ is balanced by an even distribution between 1800 and $2600 \mathrm{~m}$.

\section{CONCLUSIONS}

This study provides the first methodologically consistent glacier inventory for North Asia. The inventory substantially improves existing knowledge for this region. We applied a methodology that utilizes the contrast between the VIS and SWIR reflectance of snow and ice to identify glacier surfaces, along with automated steps to minimize issues of uneven illumination due to topographic shadowing and cloud cover, seasonal snow and patchiness. We describe an effective manual procedure to correct automatically derived glacier outlines. Manual corrections are applied to identify debris cover, seasonal snow, silty water, glaciers in deep shadow and other surface types that cannot be distinguished using solely automated methods. The automated portion of these methods constitutes a straightforward replicable 
process to produce consistent basic glacier outlines using Landsat imagery, while the manual correction portion provides a clear methodology for further refinement of the automatically generated outlines.

Results of this study provide a $\sim 2010$ North Asia glacierized area that is much smaller than previous measurements. The inventory has known errors of omission for debris-covered glacier area on complexes smaller than $2.5 \mathrm{~km}^{2}$, but the uncertainty is limited since small complexes make up less than half $(40 \%)$ of the area of the total inventory. A larger source of uncertainty arises from errors of commission due to seasonal snow, particularly for regions where the highest-quality imagery (e.g. C3b level correction) is not available. While our process of manual correction eliminated many sources of uncertainty, distinguishing between seasonal snow and glacier ice can be very difficult in some conditions. However, false identification of seasonal snow generally affects small glaciers more than larger complexes, and these do not make up a large percentage of the total area so we expect total errors to be small on regional scales. Future work incorporating more highresolution imagery would greatly reduce these uncertainties. The inventory presented here will allow future research to focus on assessing glacier changes, total volume and hydrologic modelling.

\section{ACKNOWLEDGEMENTS}

We thank C. Kienholz for providing delineation Python scripts and advice on using them, G. Cogley for directing us to relevant references and for editorial comments, A. Pope for identifying glaciers missed in an early version of the inventory, J. Rogan for providing computer facilities to conduct the initial stages of the analysis, K. Frey for comments on early versions of the manuscript, two anonymous reviewers for constructive comments, and USGS EROS and Google for making the data publicly available. Funding for A. Gardner's effort was supported by NASA's Cryosphere program. Part of the research was carried out at the Jet Propulsion Laboratory, California Institute of Technology, under a contract with the National Aeronautics and Space Administration

\section{REFERENCES}

Aleshkoff AN (1933) The glaciers of the Northern Urals. Scot. Geogr. Mag., 49(6), 359-362

Ananicheva MD, Koreisha MM and Takahashi S (2005) Assessment of glacier shrinkage from the maximum in the Little Ice Age in the Suntar-Khayata Range, North-East Siberia. Bull. Glaciol. Res., 22(1), 9-17

Ananicheva MD, Krenke AN and Hanna E (2008) Mountain glaciers of NE Asia in the near future: a projection based on climateglacier systems' interaction. Cryosphere Discuss., 2(1), 1-21

Aniya M, Sato H, Naruse R, Skvarca P and Casassa G (1996) The use of satellite and airborne imagery to inventory outlet glaciers of the Southern Patagonian Icefield, South America. Photogramm. Eng. Remote Sens., 62(12), 1361-1369

Beniston M (2003) Climatic change in mountain regions: a review of possible impacts. Climatic Change, 59, 5-31

Bolch T, Buchroithner M, Pieczonka T and Kunert A (2008) Planimetric and volumetric glacier changes in the Khumbu Himal, Nepal, since 1962 using Corona, Landsat TM and ASTER data. J. Glaciol., 54(187), 592-600 (doi: 10.3189/ 002214308786570782)
Chavez PS (1988) An improved dark-object subtraction technique for atmospheric scattering correction of multispectral data. Remote Sens. Environ., 24(3), 459-479 (doi: 10.1016/00344257(88)90019-3)

Cogley JG (2009) A more complete version of the World Glacier Inventory. Ann. Glaciol., 50(53), 32-38 (doi: 10.3189/ 172756410790595859)

Cogley J G and 10 others (2011) Glossary of glacier mass balance and related terms. (IHP-VII Technical Documents in Hydrology No. 86, IACS Contribution No. 2) UNESCO-International Hydrological Programme, Paris

Dolgushin LD (1961) Main features of the modern glaciation of the Urals. IAHS Publ. 54 (General Assembly of Helsinki - Snow and Ice)(1), 335-347

Global Land Ice Measurements from Space (GLIMS) and National Snow and Ice Data Center (NSIDC) (2005) GLIMS Glacier Database. National Snow and Ice Data Center, Boulder, CO http://dx.doi.org/10.7265/N5V98602

Gratton DJ, Howarth PJ and Marceau DJ (1990) Combining DEM parameters with Landsat MSS and TM imagery in a GIS for mountain glacier characterization. IEEE Trans. Geosci. Remote Sens., 28, 766-769

Gurney SD, Popovnin VV, Shahgedanova M and Stokes CR (2008) A glacier inventory for the Buordakh Massif, Cherskiy Range, Northeast Siberia, and evidence for recent glacier recession. Arct. Antarct. Alp. Res., 40(1), 81-88 (doi: 10.1657/1523-0430(06042)[GURNEY]2.0.CO;2)

Huggel C, Kääb A, Haeberli W, Teysseire P and Paul F (2002) Remote sensing based assessment of hazards from glacier lake outbursts: a case study in the Swiss Alps. Can. Geotech. J., 39(2), 316-330 (doi: 10.1139/t01-099)

Kadota T and Gombo D (2007) Recent glacier variations in Mongolia. Ann. Glaciol., 46,185-188 (doi: 10.3189/ 172756407782871675)

Kamp U, McManigal KG, Dashtseren A and Walther M (2013) Documenting glacial changes between 1910, 1970, 1992 and 2010 in the Turgen Mountains, Mongolian Altai, using repeat photographs, topographic maps, and satellite imagery. Geogr. J., 179(3), 248-263 (doi: 10.1111/j.1475-4959.2012.00486.x)

Khromova T, Nosenko G, Kutuzov S, Muraviev A and Chernova L (2014) Glacier area changes in Northern Eurasia. Environ. Res. Lett., 9(1), 015003 (doi: 10.1088/1748-9326/9/1/015003)

Kienholz, C, Hock R and Arendt AA (2013) A new semi-automatic approach for dividing glacier complexes into individual glaciers. J. Glaciol., 59(217), 925-937 (doi: 10.3189/2013JoG12J138)

Konya K, Kadota T, Yabuki H and Ohata T (2014) Fifty years of meteo-glaciological change in Toll Glacier, Bennett Island, De Long Islands, Siberian Arctic. Polar Sci., 8(2), 86-95 (doi: 10.1016/j.polar.2013.10.002)

Kotlyakov VM (1980) Problems and results of studies of mountain glaciers in the Soviet Union. IAHS Publ. 126 (Riederalp Workshop 1978 - World Glacier Inventory), 129-137

Kotlyakov VM and 8 others (2005) Glaciers of the former Soviet Union. In Williams RS Jr and Ferrigno JG eds, Satellite image atlas of glaciers of the world. US Geol. Surv. Prof. Pap. 1386-F-1

Kotlyakov VM, Khromova TE, Zverkova NM, Chernova LP and Nosenko GA (2011) Two new glacier systems in northeastern Eurasia. Dokl. Earth Sci., 437(1), 374-379 (doi: 10.1134/ S1028334-11030056)

Leclercq PW, Oerlemans J and Cogley JG (2011) Estimating the glacier contribution to sea-level rise for the period 1800-2005. Surv. Geophys., 32(4-5), 519-535 (doi: 10.1007/s10712-0119121-7)

Meier MF and 7 others (2007) Glaciers dominate eustatic sea-level rise in the 21 st century. Science, 317(5841), 1064-1067 (doi: 10.1126/science.1143906)

Muraviev AY and Nosenko GA (2013) Glaciation change in the northern part of the middle range on Kamchatka Peninsula in the second half of the XX century. Ice Snow, 2(1), 5-12 
Narama C, Kääb A, Duishonakunov M and Abdrakhmatov K (2009) Spatial variability of recent glacier area changes in the Tien Shan Mountains, Central Asia, using Corona ( 1970), Landsat ( 2000), and ALOS ( 2007) satellite data. Global Planet. Change, 71(1), 42-54 (doi: 10.1016/j.gloplacha.2009.08.002)

Nuimura T and 12 others (2014) The GAMDAM Glacier Inventory: a quality controlled inventory of Asian glaciers. Cryosphere Discuss., 8(1), 2799-2829

Oerlemans J and Fortuin JPF (1992) Sensitivity of glaciers and small ice caps to greenhouse warming. Science, 258(5079), 115-117 (doi: 10.1126/science.258.5079.115)

Osipov EY and Osipova OP (2014) Mountain glaciers of southeast Siberia: current state and changes since the Little Ice Age. Ann. Glaciol., 55(66), 167-176 (doi: 10.3189/2014AoG66A135)

Paul F (2000) Evaluation of different methods for glacier mapping using Landsat TM. In Buchroithner MF ed. Proceedings of 20th EARSeL Symposium - Land Ice and Snow, 14-16 June, Dresden, Germany. European Association of Remote-Sensing Laboratories, Münste, 239-245

Paul F, Kääb A, Maisch M, Kellenberger T and Haeberli W (2002) The new remote-sensing-derived Swiss glacier inventory: I. Methods. Ann. Glaciol., 34, 355-361 (doi: 10.3189/ 172756402781817941)

Paul F, Huggel C and Kääb A (2004) Combining satellite multispectral image data and a digital elevation model for mapping debris-covered glaciers. Remote Sens. Environ., 89(4), 510-518 (doi: 10.1016/j.rse.2003.11.007)

Paul F and 19 others (2013) On the accuracy of glacier outlines derived from remote-sensing data. Ann. Glaciol., 54(63), 171-182 (doi: 10.3189/2013AoG63A296)

Pfeffer WT and 18 others (2014) The Randolph Glacier Inventory: a globally complete inventory of glaciers. J. Glaciol., $\mathbf{6 0}(221)$, 537-552 (doi: 10.3189/2014JoG13J176)

Racoviteanu AE, Williams MW and Barry RG (2008) Optical remote sensing of glacier characteristics: a review with focus on the Himalaya. Sensors, 8, 3355-3383 (doi: 10.3390/s8053355)

Racoviteanu AE, Paul F, Raup B, Khalsa SJS and Armstrong R (2009) Challenges and recommendations in mapping of glacier parameters from space: results of the 2008 Global Land Ice Measurements from Space (GLIMS) workshop, Boulder, Colorado, USA. Ann. Glaciol., 50(53), 53-69 (doi: 10.3189/ 172756410790595804)

Shahgedanova M (2002) Climate at present and in the historical past. In The physical geography of northern Eurasia. Oxford University Press, Oxford, 70-102

Shahgedanova M, Nosenko G, Khromova T and Muraveyev A (2010) Glacier shrinkage and climatic change in the Russian Altai from the mid-20th century: an assessment using remote sensing and PRECIS regional climate model. J. Geophys. Res. Atmos., 115 D16107 (doi: 10.1029/2009JD012976)

Shahgedanova M, Popovnin V, Aleynikov A and Stokes CR (2011) Geodetic mass balance of Azarova glacier, Kodar Mountains, eastern Siberia, and its links to observed and projected climatic change. Ann. Glaciol., 52(58), 129-137 (doi: 10.3189/ 172756411797252275

Shahgedanova M, Nosenko G, Bushueva I and Ivanov M (2012) Changes in area and geodetic mass balance of small glaciers, Polar Urals, Russia, 1950-2008. J. Glaciol., 58(211), 953-964 (doi: 10.3189/2012JoG11J233)

Shi Y, Mi D, Yao T, Zeng Q and Liu C (2005) Glaciers of China. In Williams RS Jr and Ferrigno JG eds, Satellite image atlas of glaciers of the world. US Geol. Surv. Prof. Pap. 1386-F-?

Sidjak RW and Wheate RD (1999) Glacier mapping of the Illecillewaet Icefield, British Columbia, Canada, using Landsat TM and digital elevation data. Int. J. Remote Sens., 20(2), 273-284 (doi: 10.1080/014311699213442)

Stokes CR, Shahgedanova M, Evans IS and Popovnin VV (2013) Accelerated loss of alpine glaciers in the Kodar Mountains, southeastern Siberia. Global Planet. Change, 101(1), 82-96 (doi: 10.1016/j.gloplacha.2012.12.010)

Surazakov AB, Aizen VB, Aizen EM and Nikitin SA (2007) Glacier changes in the Siberian Altai Mountains, Ob River basin (19522006) estimated with high resolution imagery. Environ. Res. Lett., 2(4), 045017 (doi: 10.1088/1748-9326/2/4/045017)

Svoboda F and Paul F (2009) A new glacier inventory on southern Baffin Island, Canada, from ASTER data: I Applied methods, challenges and solutions. Ann. Glaciol., 50(53), 11-21 (doi: 10.3189/172756410790595912)

United States Geological Survey (USGS) (2013) LDCM cal/val algorithm description document version 3.0. USGS, Sioux Falls, SD http://landsat.usgs.gov/documents/LCDM/_CVT_ADD.pdf

Welch R, Jordan TR and Ehlers M (1985) Comparative evaluations of the geodetic accuracy and cartographic potential of Landsat-4 and Landsat-5 thematic mapper image data. J. Photogramm. Eng. Remote Sens., 51, 1249-1262

WGMS (1989) World glacier inventory: status 1988, ed. Haeberli W, Bösch H, Scherler K, Østrem G and Wallén CC. IAHS (ICSI)/ UNEP/UNESCO, World Glacier Monitoring Service, Zürich

Williams RS Jr, Hall DK and Benson C (1991) Analysis of glacier facies using satellite techniques. J. Glaciol., 37(125), 120-128

Zhang M, Wang S, Li Z and Wang F (2012) Glacier area shrinkage in China and its climatic background during the past half century. J. Geogr. Sci., 22(1), 15-28 (doi: 10.1007/s11442-012-0908-3) 